\title{
Modifiable Risk Factors associated with Post-Operative Bleeding and transfusion requirements in Cardiac Surgery
}

\author{
Bahauddin Khan ${ }^{1}$, Mujahid Ul Islam², \\ Imtiaz Ahmad ${ }^{3}$, Mujeeb Ur Rehman ${ }^{4}$
}

\begin{abstract}
Objectives: In this study we determine the modifiable factors related to bleeding and transfusion in postcardiac surgery patients who underwent open heart surgery.

Methods: This is a retrospective study that include two hundred patients who had undergone open heart surgery (OHS) at Northwest General Hospital and Research Center from December 2018 to July 2021. Platelet count and hemoglobin level were measured in the pre-operative period.

Results: This study included both male and female patients. Postoperative platelets were counted as follow: $50-100 \times 10^{9} \mathrm{~L}$ in $3.0 \%$ cases, $101-150 \times 10^{9} \mathrm{~L}$ seen in $27.5 \%$ cases, and $>150 \times 10^{\circ} \mathrm{L}$ in $69.5 \%$ cases which required transfusion. We have also reported the increased requirement of transfusion of blood and blood products in patients with pre-operative hemoglobin $(\mathrm{Hb})<10 \mathrm{~g} / \mathrm{dl}$.

Conclusion: Correction of pre-op $\mathrm{Hb}$, post-op platelet count and total bypass time are the significant and preventable parameters in patients undergoing cardiac surgery if proper pre-op assessment of the patient is performed.
\end{abstract}

KEYWORDS: Bleeding, Cardiopulmonary bypass, Open heart surgery, Hemoglobin, Platelets.

How to cite this:

doi: https://doi.org/10.12669/pjms.38.4.5685

Khan B, Mujahid UI Islam, Ahmad I, Mujeeb Ur Rehman. Modifiable Risk Factors associated with Post-Operative Bleeding and transfusion requirements in Cardiac Surgery. Pak J Med Sci. 2022;38(4):855-861.

doi: https://doi.org/10.12669/pjms.38.4.5685

This is an Open Access article distributed under the terms of the Creative Commons Attribution License (http://creativecommons.org/licenses/by/3.0), which permits unrestricted use, distribution, and reproduction in any medium, provided the original work is properly cited.

1. Dr. Bahauddin Khan, FCPS. Assistant Professor,

Department of Cardiothoracic Surgery,

2. Dr. Mujahid UI Islam, FCPS Associate Professor, Department of Anesthesia,

3. Dr. Imtiaz Ahmad, FCPS. Associate Professor, Department of Anesthesia,

4 Dr. Mujeeb Ur Rehman, MS. Senior Registrar,

Department of Cardiovascular Surgery,

Lady Reading Hospital,

Peshawar, Pakistan.

1-3: Rehman Medical Institute,

Peshawar, Pakistan.

Correspondence:

Dr. Mujeeb Ur Rehman, MBBS, MS.

Cardiovascular Surgery Unit,

Lady Reading Hospital, Peshawar, Pakistan.

Email: drmujeebdawar45@gmail.com

* Received for Publication:

* $1^{\text {st }}$ Revision Received:

* $2^{\text {nd }}$ Revision Received:

* Corrected \& Edited:

* Final Revision Accepted:

\section{INTRODUCTION}

Bleeding and transfusion of blood and blood products is a serious concern in patients undergoing cardiac surgery. ${ }^{1}$ Some of the significant factors including deficiency of coagulation factor, an improper heparin reversal, raised fibrinolytic state, platelet deficiency and technical causes. The surgical technical causes have been reported the leading cause of coagulopathic condition..$^{1-3}$ The definite cause of bleeding is not easy to define. This is started with replacement of volume and transfusion of blood, FFP and platelet transfusion, infusion of tranexamic acid. In certain cases, correction of acidosis, regulation of blood glucose level, reversal of hypothermia, mechanical and chemical inotropic support standardization, correction and monitoring of cardiac rhythm are important to prevent bleeding. ${ }^{4,5}$ Use of Thrombo Elastography (TEG) is important to know the underlying pathology. The ultimate option to identify and treat the factor of 
bleeding in 2 to $11 \%$ of cases is chest exploration. ${ }^{6}$ Most common causes of Excessive postoperative bleeding $(75 \%)$ of cases are from surgical origins. ${ }^{6,7}$

The surgical factor of bleeding requiring reexploration reported from $35-100 \%{ }^{8}$ It is usually at the sites of anastomosis, conduits side branches, soft tissues under the sternum, suture sites of the sternum, periosteum and bone marrow. ${ }^{2}$ Antiplatelet medications are also leading to platelet defects in acute coronary disease patients resulting in platelet dysfunction in Preoperative condition. ${ }^{8}$ Clopidogrel and Aspirin are the commonly used drugs in cardiac surgery patients. ${ }^{5}$ Increase reexploration rate has been reported in Clopidogrel taking patients. ${ }^{9}$ Preoperative Platelet count (< $\left.100 \times 10^{9}\right) \mathrm{L}$ is a dreadful cause of postoperative bleeding and blood transfusion requirements. ${ }^{10}$ Cardiopulmonary bypass machine has been shown the significant cause of intraoperative coagulopathy ${ }^{8}$ It is reported that Prolonged crossclamp time is the significant factor of profuse postop bleeding. Body temperature of 33 Celsius or less affects the adhesion and Platelet aggregation. The "heparin rebound" phenomenon has reported a significant factor of immediate post-op bleeding. ${ }^{11}$ Blood transfusion is a life-saving intervention in active postoperative bleeding. Blood transfusion is having adverse reactions, such as volume overload, hypothermia, potassium, calcium, magnesiumrelated disorders, acute lung injury, renal damage, infection transmission. ${ }^{12}$ The intensity and frequency of these complications are leading to the number of units transfused. Therefore, factors promoting bleeders should be controlled in the preoperative, intraoperative, and post-operative period..$^{13}$
Preoperative clopidogrel and warfarin cessation, treating infections, avoiding surgery immediately after thrombolysed patients, correcting anemia, avoiding surgery in menstruating females, optimizing liver function, diagnosing and preparation for rare coagulation anomalies, management etc., are some common causes which should be corrected, if possible, prior to surgery..$^{13,14}$

Postoperative blood transfusion, FFPs, platelets concentrate, tranexamic acid and High PEEP for the bleeders to get tamponade, temperature regulation, correcting the acidosis are the concern for the excessive bleeding. ${ }^{14-17}$ If there is hemodynamics instability then early and immediate chest reexploration should be considered to remove the clot in the chest. Early reopening has been considered to avoid extra blood transfusions and the patient's physiological reserve. ${ }^{18}$

The clinical significance of this study is; Pre-op $\mathrm{Hb}$, platelets count and bypass pass time have been shown that greatly affect bleeding and transfusion requirement in post-op cardiac patients.

\section{METHODS}

The retrospective study was conducted in the cardiac surgery unit at North West General Hospital and Research Center, Peshawar from December 2018 to July 2021. A total of two hundred patients underwent open heart surgery during this period. After acquiring ethical approval from the research and ethical committee (Ref\# NwGH/Res/Ethical Approval/1441, of the institute. data was retrieved from Hospital Management Information System (HMIS). Pre-op Hb, post-op platelet count, and total bypass time are analyzed in this study.

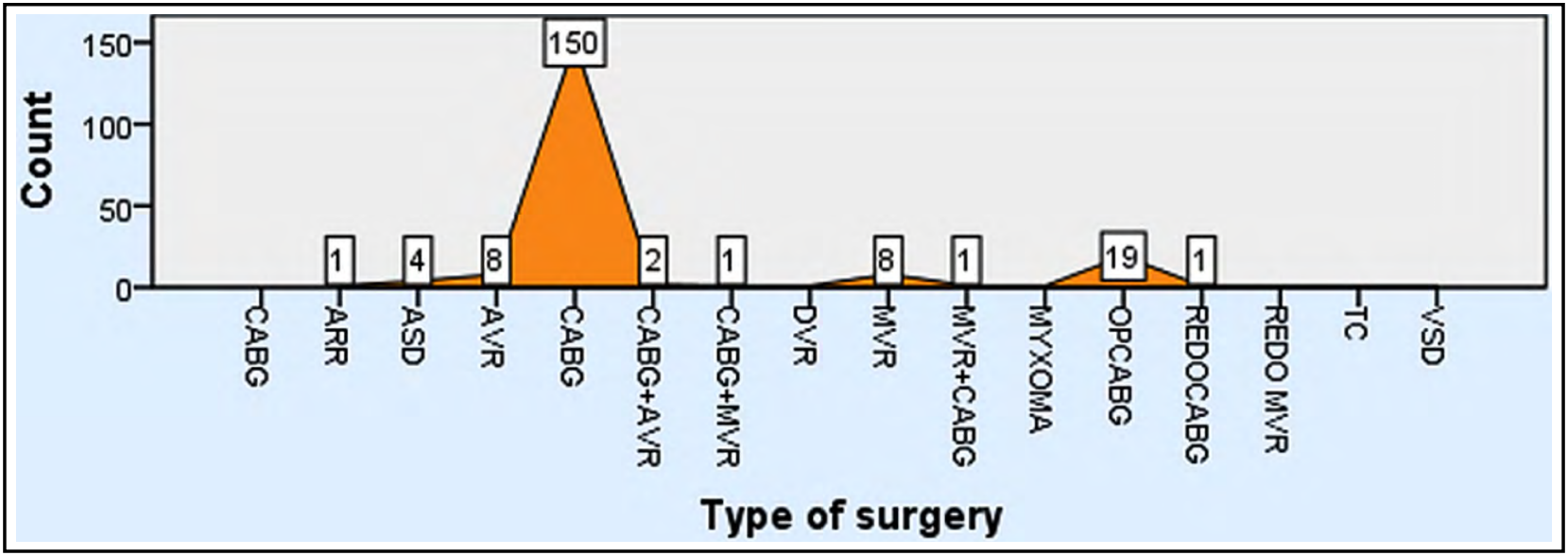

Fig.1: Procedures Breakup.

Abbreviation: ASD: Atrial Septal Defect, VSD: Ventricular Septal Defect, AVR: Aortic Valve, Replacement, DVR: Double Valve Replacement, OPCABG: Off-Pump Coronary Artery Bypass Grafting, MVR: Mitral Valve Replacement, TC: Total Correction, REDO: Re-Opening cases. 
Table-I: Association of Preoperative Hemoglobin Level with post-op transfusion.

\begin{tabular}{lccc}
\hline $\begin{array}{l}\text { Hemoglobin } \\
\text { range }(\mathrm{g} / \mathrm{dl})\end{array}$ & Frequency & Percentage & $\begin{array}{c}\text { Number of } \\
\text { transfusions }\end{array}$ \\
\hline$<10$ & 3 & $1.5 \%$ & 5 \\
$10.0_{-} 11.0$ & 6 & $3.0 \%$ & 4 \\
$11.1_{-} 12.0$ & 14 & $7.0 \%$ & 3 \\
$12.1_{-} 13.0$ & 21 & $10.5 \%$ & 2 \\
$13.1_{-} 14.0$ & 34 & $17.0 \%$ & 1 \\
$>14$ & 122 & $61.0 \%$ & 0 \\
\hline Total & 200 & $100.0 \%$ & \\
\hline
\end{tabular}

PRE-OP Hb; Pre-operative hemoglobin,

POST-OP; post-operative.

Patients having both genders, of all ages, undergoing coronary artery bypass grafting (CABG), valve surgery (MVR, AVR, DVR), Congenital corrective procedures (ASD, VSD, TC) and off-pump bypass grafting were included in the study. We also included the patients presenting for elective cardiac surgery, with or without $\mathrm{CPB}$ respectively. On the other hand, patients with Endovascular procedures (trans-aortic valve replacement (TAVR) and all percutaneous techniques), non-cardiac thoracic operations and surgeries on the descending aorta were not included in this study.

SPSS (statistical package for social sciences) version 22 was used for data analysis. Descriptive statistics (mean, frequencies and percentage) were applied to analyze data of the study subjects. Frequencies and percentage of the study variables were calculated and data represented graphically (bar graph, pie chart etc.) as well as in the description.

\section{RESULTS}

Age distribution breakup of 200 patients was as follows, $4(2.0 \%)$ patients were between 0-15 years, between 16-30 years fell $6(3.0 \%)$ patients,
Table-II: Patient's characteristics.

\begin{tabular}{lcc}
\hline $\begin{array}{l}\text { Number of } \\
\text { Transfusion }\end{array}$ & Frequency & $\begin{array}{c}\text { Cumulative } \\
\text { Percent }\end{array}$ \\
\hline 0 & 89 & $44.5 \%$ \\
1 & 52 & $26 \%$ \\
2 & 35 & $17.5 \%$ \\
3 & 15 & $7.5 \%$ \\
4 & 6 & $3 \%$ \\
5 & 3 & $1.5 \%$ \\
\hline Total & 200 & $100 \%$ \\
\hline As shown in Table-I, 89 (44.5\%) had no blood \\
transfusion, 52 (26.0\%) had 1 unit, 35 (17.5\%) \\
had 2 units, 15 (7.5\%) had 3 units, 6 (3.0\%) had 4 \\
units, and 3 (1.5\%) had 5 units.
\end{tabular}

$31-45$ year were $34(17.0 \%)$ patients, $46-60$ years were $93(46.5 \%)$ patients, and from age $61-75$ years were $63(31.5 \%)$ patients. Gender distribution were $30.50 \%$ (Male) and $69.50 \%$ (Female). Most common Procedure was CABG as shown in Fig.1. Postoperative platelets count $50-100 \times 109 \mathrm{~L}$ in $3.0 \%$ cases, $101-150 \times 109 \mathrm{~L}$ seen in $27.5 \%$ cases, $>150 \times$ $109 \mathrm{~L}$ count seen in $69.5 \%$ cases.

The Pre-operative $\mathrm{Hb}$ level has been shown in Table-I and was commonly more than $14 \mathrm{~g} / \mathrm{dl}$ in $(61 \%)$ patients and was less than $11 \mathrm{~g} / \mathrm{dl}$ in less number of patients such as $10.0-11.0 \mathrm{~g} / \mathrm{dl}$ in $3.0 \%$ and $<10 \mathrm{~g} / \mathrm{dl}$ in $1.5 \%$ patients. Low pre-op $\mathrm{Hb}$ resulting in increased post-op transfusion requirements as shown in Table II. $61 \%$ patients with pre-op $\mathrm{Hb}>14$ did not require any post-op transfusion. There were maximum number of patients $(17.0 \%)$ with $\mathrm{Hb} 13.1$ - 14.0, who received one transfusion. Maximum number of transfusions have been given to patients with $\mathrm{Hb}<10$. This table is based on the number of transfusions on the basis of $\mathrm{Hb}$. Table-II

As can be seen in Table-III, total blood volume lost is proportional to the bypass time which perfectly corresponds to published literature.

Table-III: Association of Total Bypass time with Post-operative Bleeding.

\begin{tabular}{lccccc}
\hline \multirow{2}{*}{ Post-operative bleeding } & \multicolumn{4}{c}{ Total Bypass time } & \multirow{2}{*}{ Total } \\
\cline { 2 - 5 } & $<60$ & $61-120$ & $>120$ & \multirow{2}{*}{ OPCABG } \\
\hline $0-250$ & $5.9 \%$ & $1.4 \%$ & & $1.5 \%$ \\
$251-500$ & $11.8 \%$ & $17.6 \%$ & $6.7 \%$ & $25.0 \%$ & $17.0 \%$ \\
$501-750$ & $41.2 \%$ & $50.7 \%$ & $80.0 \%$ & $55.0 \%$ & $52.5 \%$ \\
$>750$ & $41.2 \%$ & $30.4 \%$ & $13.3 \%$ & $20.0 \%$ & $29.0 \%$ \\
\hline Total & $100.0 \%$ & $100.0 \%$ & $100.0 \%$ & $100.0 \%$ & $100.0 \%$ \\
\hline
\end{tabular}




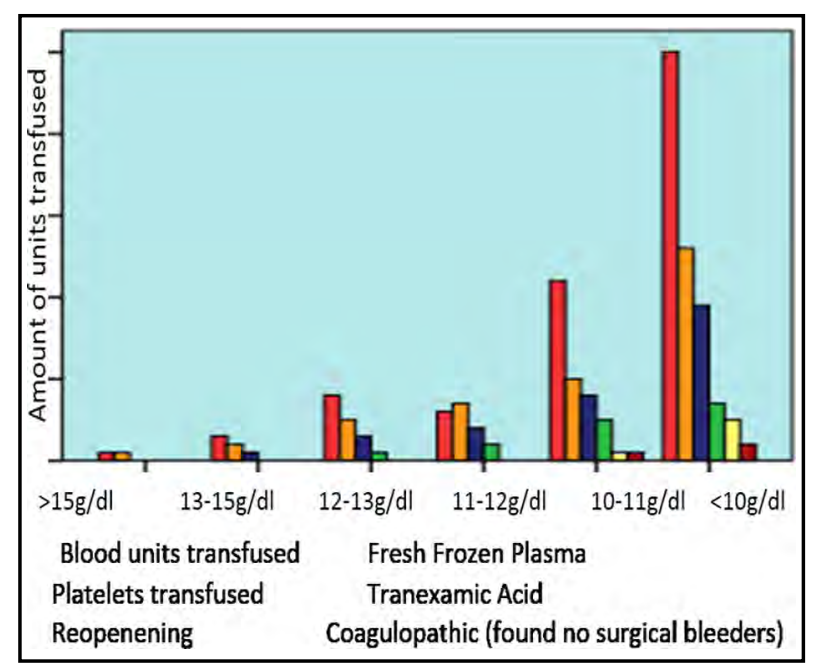

Fig.2: Association of Pre-Operative Hemoglobin Level with chest re-opening, post-op blood and blood products requirements'.

Bypass time is a significant factor of bleeding in cardiac surgery patients as it greatly affects the platelet count. Table-IV. There were $85.0 \%$ patients with PLT count of $>150 \times 10^{\circ} \mathrm{L}$ in OPCAB patients and PLT count $(>150 \times 109) \mathrm{L}$ was shown in $60.0 \%$ of patients with bypass time of $>120$ minutes. Moreover, the PLT count was $(>150 \times 109) \mathrm{L}$ in $76.5 \%$ patients with bypass time $<60$ minutes.

Our study has further illustrated that hemoglobin level alone has a major effect on post-operative transfusion requirement, fresh frozen plasma requirement, platelets transfusion requirement, chest reopening requirement, and coagulopathy (Fig.2).

With preoperative hemoglobin above $15 \mathrm{~g} / \mathrm{dl}$, only one patient required blood and fresh frozen plasma transfusion, as pre-operative hemoglobin level decreases the amount of blood and blood products required also increased. Below $10 \mathrm{~g} / \mathrm{dl}$ pre-operative levels the requirement of blood and blood products are common as opposed to more than $15 \mathrm{~g} / \mathrm{dl}$.

\section{DISCUSSION}

Bleeding Academic Research Consortium (BARC reported that 5 or more units of packed red blood cells (PRBCs) transfusions in 48 Hours and greater than 2 liters of chest tube output in 24 Hours are said to be significant in cardiac surgery patients. ${ }^{5}$ Patients that bleed actively can be taken to these summits rarely and early steps for optimization are usually necessary including the use of blood products, blood, medical optimization and reoperation. This is only possible with proper preoperative assessment of the patient. ${ }^{6}$ Correction of acidosis and hypothermia are the entity leading to decrease bleeding. The small bleeders can be tamponade by keeping the PEEP of around $10 \mathrm{~cm}$. These parameters can be achieved in order to assess the cause and status of profuse bleeding such as complete blood count, Thromboelastography, Prothrombin time, Activated thromboplastin time and fibrinogen levels. ${ }^{6,11}$ To improve the coagulation, Platelets transfusion, Fresh Frozen Plasma, and occasionally Desmopressin are the important parameters. Additional Protamine can be used to treat the Heparin rebounding phenomenon. Coagulopathy can be treated with a novel agent such as Recombinant factor VII. Aminocaproic acid and Tranexamic acid have frequent use too. ${ }^{19}$ The Commonly used and avoiding Preoperative associated factors leading to postoperative bleeding are Clopidogrel which should be stopped five days before the surgery, Ticagrelor which should be stopped three days before the operation, Heparin for acute coronary syndromes, low molecular weight heparin and patients on Warfarin or novel oral anticoagulants as these factors are not analyzed in our study. Common causes of excessive bleeding are extra cardiac bleeders, LIMA bed, and surgical bleeders from either distal or proximal anastomosis sites. That is why; it is quite complicated to ensure proper hemostasis. ${ }^{11}$

Table-IV: Association of Total Bypass time with Post-operative platelets count.

\begin{tabular}{|c|c|c|c|c|c|c|}
\hline \multirow{2}{*}{ Post-operative platelets count } & & \multicolumn{4}{|c|}{ Total Bypass time } & \multirow{2}{*}{ Total } \\
\hline & & $<60$ & $61-120$ & $>120$ & $O P C A B$ & \\
\hline & $50-100$ & & $4.1 \%$ & & & $3.0 \%$ \\
\hline & $101-150$ & $23.5 \%$ & $28.4 \%$ & $40.0 \%$ & $15.0 \%$ & $27.5 \%$ \\
\hline & $>150$ & $76.5 \%$ & $67.6 \%$ & $60.0 \%$ & $85.0 \%$ & $69.5 \%$ \\
\hline Total & & $100.0 \%$ & $100.0 \%$ & $100.0 \%$ & $100.0 \%$ & $100.0 \%$ \\
\hline
\end{tabular}

OPCAB; Off-pump Coronary Artery Bypass. 
Different Intraoperative common methods to avoid bleeding include clip application, stitching, and ligation for significant identified points. It is reported that the success rate of intraoperative Fibrin sealant or topical hemostatic agents is $92.6 \%{ }^{16}$ It has been suggested that delayed sternal wound closure will get rid of later clot removal and tamponade. ${ }^{18}$

Multiple Causes of excessive bleeding have been reported recently in cardiac surgery patients such as $74 \%$ cases are due to technical or mechanical reasons, coagulopathy $(13 \%)$, combination $(10 \%)$ and others 3\%. ${ }^{6-10}$ Technical factors are the most common reasons for reoperations for bleeding. ${ }^{20}$

The function of preoperative hemoglobin is well identified in recognizing the significance of factors related to adverse outcomes. ${ }^{21}$ Assessing the quality of the preoperative platelets in openheart surgery patients would decrease the frequency of hemorrhage and blood transfusion. ${ }^{22}$ A recently reported meta-analysis, that included $>3,000$ patients reported that platelet dysfunction in patients undergoing cardiac surgery can be determine by Point of Care (POC) platelet function tests perioperatively. ${ }^{22,23}$ Platelet function and coagulation system are strongly affected by Cardiopulmonary bypass (CPB) via different mechanisms, like hemodilution leading to decrease platelet count, artificial surfaces resulting in contact activation, bypass-induced platelet activation, massive doses of heparin, reversal of heparin with protamine, hypothermia and reduced hemoglobin. ${ }^{24,25}$

Recently reported studies stated that monitoring of platelet function are feasible and beneficial during and after $\mathrm{CPB} .{ }^{26-28} \mathrm{ADP}$ activation test might be useful to determine the $\mathrm{CPB}$ effect on platelet function. ${ }^{29}$ Assessment of preoperative platelet function would result in decrease frequency of postoperative bleeding and blood transfusion as compared to those of the postoperative evaluation. ${ }^{25}$ It has been reported in a local study that bypass time doesn't affect the post-op platelets. ${ }^{30}$ But our study reported that total bypass time has a significant effect on postoperative platelet count as shown in Table-IV as the amount of platelet decreased by increasing the bypass time and vice versa.

Platelet dysfunction is a significant cause of postoperative bleeding in cardiac surgery patients. The association between platelet function and severe bleeding was defined by Operating Room (PLATFORM) study after CPB, giving the platelet function adequate predictive values for massive bleeding. A cohort trial on 490 adult cardiac surgery patients with $\mathrm{CPB}$ reported that TRAPtest and ADPtest post-CPB had significant massive bleeding $(\mathrm{P}=0.001) .{ }^{31}$ we did not use this test and will consider it for future studies.

Platelet dysfunction in cardiac surgery resulting in bleeding due to contact with the surfaces of non-biological cardiopulmonary bypass (CPB) machine. ${ }^{26}$ However, platelets permit the shear the pumping of blood poorly, getting partially activated and shed the contents of their granules. ${ }^{32}$ The platelet count decreases during the course of the surgical procedure due to their consumption in the circuit resulting in impaired function of the remaining platelets. Hence, platelet function defect and thrombocytopenia are commonly treated with transfusions of platelet in patients undergoing CPB. ${ }^{33}$

Recently reported study on 177 patients observed thrombocytopenia in $167(94.4 \%)$ patients from the baseline value. There was maximum drop in platelet count during 2nd and 3rd postoperative days. Hence, severe thrombocytopenia $\left(<50,000 \times 10^{9} / 1\right)$ was observed in $9(5.3 \%)$ patients. ${ }^{34}$ Allogeneic blood transfusion has been reported as an associated factor for hospital-acquired infection, suppression of immune, overload of circulatory system and mortality. it is also stated that tissues ischemia may occur due to restricting RBC transfusion, ultimately affecting the prognosis.

The trigger of the liberal and restrictive $R B C$ transfusion in the high-risk cardiac surgery patients $(n=5,243)$ has been only discovered by the Transfusion Requirements in Cardiac Surgery TRICS-III trial. Cardiac surgery patients were randomized in the preoperative state to a restrictive [hemoglobin $(\mathrm{Hgb})<7.5 \mathrm{~g} / \mathrm{dL}$ ] or liberal transfusion trigger $(\mathrm{Hgb}<9.5 \mathrm{~g} / \mathrm{dL}$ in the operating theater and ICT, and Hgb <8.5. The primary leading cause of myocardial infarction, stroke, death and new-onset of renal failure requiring dialysis in the restrictive group had been found non-dominant to the liberal group (11.4\% restrictive vs. $12.5 \%$ liberal $\mathrm{P}<0.001) .{ }^{35}$

It is true that blood transfusion does save many lives and it has always been a concern in cardiac surgery where blood loss is often seen. Blood is a scarce factor, and its complications must compare against the benefits. However, there is a need for the protocols of transfusion as blood transfusion increase mortality in critically ill patients. ${ }^{36}$ It has also been shown that blood transfusion shift the prognosis and outcome in anemic patients. ${ }^{37}$ many 
studies have calculated the risk of morbidity and mortality. ${ }^{38}$ According to recent studies, more conservative blood transfusion protocols are being used in various centers. ${ }^{39}$ Postoperative Infection has been reported the associated controversial risk with blood transfusion. ${ }^{40}$

It has been reported that preoperative anemia, morbidity, mortality, and higher hospital costs are associated with increased blood transfusions. ${ }^{41}$ Higher rates of stroke, acute renal injury, and total number of adverse postoperative outcomes have also been reported to be associated with preoperative anemia in cardiac surgery patients. ${ }^{42}$

Our study reported that Pre-op $\mathrm{Hb}<10 \mathrm{~g} / \mathrm{dl}$ required increase number of blood and blood products transfusion as compared to pre-op $\mathrm{Hb} 13-$ $15 \mathrm{~g} / \mathrm{dl}$ or $>15 \mathrm{~g} / \mathrm{dl}$. Our study has also showed that the requirement of postoperative blood transfusion, platelets transfusion, fresh frozen plasma, coagulopathy and chest reopening are greatly affected by preoperative hemoglobin level alone. Post-op infection and other post-op transfusionrelated complications data have not been collected. It is worth noting at this point that a multicenter prospective study would be required to further evaluate our findings.

Limitation of the study: This study has small sample size and single centered. Our study does not include the association of post-op bleeding with age, gender, pre-op platelets and weight in cardiac surgery patients. We have included all the open heart surgery patients in our study. Multicenter studies will be needed to know the post-op bleeding in individual open heart surgery patients. We did not note the details of pre-op anti platelet and anti-coagulant medications as well.

\section{CONCLUSIONS}

The preoperative evaluation and recognition of $\mathrm{Hb}$, post-op platelet quantity and function, and decreasing the total bypass time are the significant and preventable parameters related to postoperative bleeding and transfusion requirement in cardiac surgery patients. It will also decrease the ICU and hospital stay as well.

Acknowledgements: The authors thank Prof. Muhammad Rehman and Prof. Niaz Ali for their valuable suggestions regarding this study.

Conflicts of interest: None.

Grant support $\mathcal{E}$ financial disclosures: None.

\section{REFERENCES}

1. Choi YJ, Yoon SZ, Joo BJ, Lee JM, Jeon YS, Lim YJ, et al. Postoperative excessive blood loss after cardiac surgery can be predicted with International Society on Thrombosis and Hemostasis scoring system. Braz J Anesthesiol. 2017;67:508-515. doi: 10.1016/j.bjane.2016.12.001

2. DeBois W, Liu J, Lee L, Girardi L, Ko W, Tortolani A, et al. Cardiopulmonary bypass in patients with pre-existing coagulopathy. J Extra Corpor Technol. 2005;37(1):15.

3. McMillan D, Potger K, Southwell J. Blood management issues: getting clots together when you want them. J Extra Corpor Technol. 2011;43(1):P52.

4. Richard WC, Harker LA. "Bleeding complications associated with cardiopulmonary bypass." Journal name is missing 1990:1680-1697. doi: 10.1182/blood.V76.9.1680.1680

5. Kremke M, Hansen MK, Christensen S, Tang M, Andreasen JJ, Jakobsen CJ. The association between platelet transfusion and adverse outcomes after coronary artery bypass surgery. Eur J Cardiothorac Surg. 2015;48(5):e102-e129. doi: $10.1093 /$ ejcts/ezv297

6. Osei-Bimpong A, McLean R, Bhonda E, Lewis SM. The use of the white cell count and haemoglobin in combination as an effective screen to predict the normality of the full blood count. Int J Lab Hematol. 2012;34(1):91-107. doi: 10.1111/j.1751-553X.2011.01365.x

7. Choong CK, Gerrard C, Goldsmith KA, Dunningham H, Vuylsteke A. Delayed re-exploration for bleeding after coronary artery bypass surgery results in adverse outcomes. Eur J Cardiothorac Surg. 2007;31(5):834-838. doi: 10.1016/j. ejcts.2007.02.001

8. Frojd V, Jeppsson A. Reexploration for bleeding and its association with mortality after cardiac surgery. Ann Thorac Cardiovasc Surg. 2016;102(1):109-117. doi: 10.1016/j.athoracsur.2016.01.006

9. Janiec M, Nazari Shafti TZ, Dimberg A, Lagerqvist B, Lindblom RP. Graft failure and recurrence of symptoms after coronary artery bypass grafting. Scand Cardiovasc J. 2018;52(3):113-119. doi: 10.1080/14017431.2018.1442930

10. Whitson BA, Huddleston SJ, Savik K, Shumway SJ. Risk of adverse outcomes associated with blood transfusion after cardiac surgery depends on the amount of transfusion. J Surg Res. 2010;158(1):20-27. doi: 10.1016/j.jss.2008.10.015

11. Davidson S. State of the A rt-How I manage coagulopathy in cardiac surgery patients. Br J Haematol. 2014;164(6):779789. doi: $10.1111 /$ bjh. 12746

12. Tettey M, Aniteye E, Sereboe L, Edwin F, Kotei D, Tamatey $\mathrm{M}$, et al. Predictors of post operative bleeding and blood transfusion in cardiac surgery. Ghana Med J. 2009;43(2):7176. doi: 10.4314 /gmj.v43i2.55316

13. Scott BH, Seifert FC, Glass PS, Grimson R. Blood use in patients undergoing coronary artery bypass surgery: impact of cardiopulmonary bypass pump, hematocrit, gender, age, and body weight. Anesth Analg. 2003;97(4):958-963. doi: 10.1213/01.ANE.0000081790.75298.D8

14. Janiec M, Dimberg A, Nazari Shafti TZ, Lagerqvist B, Lindblom RP. No improvements in long-term outcome after coronary artery bypass grafting with arterial grafts as a second conduit: a Swedish nationwide registry study. Eur J Cardiothorac Surg. 2018;53(2):448-454. doi: 10.1093/ ejcts/ezx280

15. Pagano D, Milojevic M, Meesters MI, Benedetto U, Bolliger D, von Heymann C, et al. 2017 EACTS/EACTA Guidelines on patient blood management for adult cardiac surgery. Eur J Cardiothorac Surg. 2018;53(1):79-111. doi: 10.1093/ ejcts/ezx325 
16. Ranucci M, Bozzetti G, Ditta A, Cotza M, Carboni G, Ballotta A. Surgical reexploration after cardiac operations: why a worse outcome?. Ann Thorac Surg. 2008;86(5):1557-1562. doi: 10.1016/j.athoracsur.2008.07.114

17. Mehran R, Rao SV, Bhatt DL, Gibson CM, Caixeta A, Eikelboom J, Kaul S, Wiviott SD, Menon V, Nikolsky E, Serebruany V. Standardized bleeding definitions for cardiovascular clinical trials: a consensus report from the Bleeding Academic Research Consortium. Circulation. 2011;123(23):27362747. doi: 10.1161/CIRCULATIONAHA.110.009449

18. Zhou X, Lui C, Whitman GJ. Bleeding and Re-exploration After Cardiac Surgery. InCardiac Surgery 2020(pp:763-768). Springer, Cham. doi: 10.1007/978-3-030-24174-2_83

19. Hardy JF, Harel F, Belisle S. Transfusions in patients undergoing cardiac surgery with autologous blood. Can J Anaesth. 2000;47(7):705-711.10.1007/BF03019006.

20. Dyke C, Aronson S, Dietrich W, Hofmann A, Karkouti K, Levi $\mathrm{M}$, et al. Universal definition of perioperative bleeding in adult cardiac surgery. J Thorac Cardiovasc Surg 2014;147(5):1458-1463. doi: 10.1016/j.jtcvs.2013.10.070

21. Lopes CT, Brunori EH, Cavalcante AM, Moorhead SA, Lopes JD, Barros AL. Predictors of red blood cell transfusion after cardiac surgery: A prospective cohort study. Revista da Escola de Enfermagem da USP. 2015;49:914-922. doi: 10.1590/S0080-623420150000600006

22. Bolliger D, Lance MD, Siegemund M. Point-of-care platelet function monitoring: Implications for patients with platelet inhibitors in cardiac surgery. J Cardiothorac Vasc Anesth 2021;35(4):1049-1059. doi: 10.1053/j.jvca.2020.07.050

23. Corredor C, Wasowicz M, Karkouti K, Sharma V. The role of point-of-care platelet function testing in predicting postoperative bleeding following cardiac surgery: A systematic review and meta-analysis. Anaesthesia. 2015;70(6):715-731. doi: 10.1111/anae.13083

24. Agarwal S, Johnson RI, Kirmani BH. Pre-and post-bypass platelet function testing with multiple electrode aggregometry and TEG platelet mapping in cardiac surgery. J Cardiothorac Vasc Anesth. 2015;29(5):1272-1276. doi: 10.1053/j. jvca.2015.01.028

25. Kehara H, Takano T, Ohashi N, Terasaki T, Amano J. Platelet function during cardiopulmonary bypass using multiple electrode aggregometry: comparison of centrifugal and roller pumps. Artif Organs. 2014;38(11):924-930. doi: 10.1111/ aor.12299

26. Ranucci M, Colella D, Baryshnikova E, Di Dedda U. Effect of preoperative P2Y12 and thrombin platelet receptor inhibition on bleeding after cardiac surgery. Br J Anaesth. 2014;113(6):970-976. doi: 10.1093/bja/aeu315

27. Van Poucke S, Stevens K, Kicken C, Simons A, Marcus A, Lance M. Platelet function during hypothermia in experimental mock circulation. Artif Organs. 2016;40(3):288-293. doi: 10.1111/aor.12555

28. Lax M, Pesonen E, Hiippala S, Schramko A, Lassila R, Raivio P. Heparin Dose and Point-of-Care Measurements of Hemostasis in Cardiac Surgery-Results of a Randomized Controlled Trial. J Cardiothorac Vasc Anesth. 2020;34(9):2362-2368. doi: 10.1053/j.jvca.2019.12.050

29. Ranucci M, Baryshnikova E, Soro G, Ballotta A, De Benedetti D, Conti D Surgical and Clinical Outcome Research (SCORE) Group. Multiple electrode whole-blood aggregometry and bleeding in cardiac surgery patients receiving thienopyridines. Ann Thorac Surg. 2011;91(1):123-129. doi: 10.1016/j.athoracsur.2010.09.022

30. Haider Z, Jalal A, Alamgir AR, Rasheed I. Neurological complications are avoidable during CABG. Pak J Med Sci. 2018;34(1):5. doi: 10.12669/pjms.341.14114
31. Ranucci M, Pistuddi V, Di Dedda U, Menicanti L, De Vincentiis C, Baryshnikova E. Platelet function after cardiac surgery and its association with severe postoperative bleeding: the platform study. Platelets. 2019;30(7):908-914. doi: 10 $.1080 / 09537104.2018 .1535706$

32. Harker LA, Malpass TW, Branson HE, Hessel E, Slichter SJ. Mechanism of abnormal bleeding in patients undergoing cardiopulmonary bypass: Acquired transient platelet dysfunction associated with selective a-granule release. Blood. 1980;56(5):824-834. doi: 10.1182/blood.V56.5.824.824

33. Perek B, Stefaniak S, Komosa A, Perek A, Katynska I, Jemielity M. Routine transfusion of platelet concentrates effectively reduces reoperation rate for bleeding and pericardial effusion after elective operations for ascending aortic aneurysm. Platelets. 2016;27(8):764-770. doi: 10.1080/09537104.2016.1184748

34. Hamid M, Akhtar MI, Naqvi HI, Ahsan K. Incidence and pattern of thrombocytopenia in cardiac surgery patients. J Pak Med Assoc. 2017;67(7):1019-1023.

35. Chow JH, Mazzeffi MA, Tanaka KA. Teaching an old dog new TRICS: re-evaluating transfusion triggers in highrisk cardiac surgery. J Thorac Dis 2018;10(2):674-677. doi: $10.21037 /$ jtd.2018.01.78

36. Gattinoni L, Brazzi L, Pelosi P, Latini R, Tognoni G, Pesenti A, Fumagalli R. A trial of goal-oriented hemodynamic therapy in critically ill patients. N Engl J Med. 1995;333(16):10251032. doi: 10.1056/ NEJM199510193331601

37. Boyd O, Grounds RM, Bennett ED. A randomized clinical trial of the effect of deliberate perioperative increase of oxygen delivery on mortality in high-risk surgical patients. JAMA. 1993;270(22):2699-2707. doi: 10.1001/ jama.1993.03510220055034

38. Horvath KA, Acker MA, Chang H, Bagiella E, Smith PK, Iribarne A, Kron IL, Lackner P, Argenziano M, Ascheim DD, Gelijns AC. Blood transfusion and infection after cardiac surgery. Ann. Thorac. Surg. 2013;95(6):2194-201. doi: 10.1016/j.athoracsur.2012.11.078.

39. Abukhodair AW, Alqarni MS, Bukhari ZM, Qadi Sr A, Mufti HN, Fernandez JA, et al. Association between post-operative infection and blood transfusion in cardiac surgery. Cureus. 2020;12(7). doi: 10.7759/cureus.8985

40. Bhaskar B, Dulhunty J, Mullany DV, Fraser JF. Impact of blood product transfusion on short and long-term survival after cardiac surgery: More evidence. Ann Thorac Surg. 2012;94(2):460-467. doi: 10.1016/j.athoracsur.2012.04.005

41. Tankard KA, Park B, Brovman EY, Bader AM, Urman RD. The impact of preoperative intravenous iron therapy on perioperative outcomes in cardiac surgery: A systematic review. Br J Haematol. 2020;9(4):97. doi: 10.14740/jh696

42. Froessler B, Rueger AM, Connolly MP. Assessing the costs and benefits of perioperative iron deficiency anemia management with ferric carboxymaltose in Germany. Risk Manag Healthcare Policy. 2018;11:77. doi: 10.2147/RMHP. S157379

\section{Authors' Contribution:}

MUR \& BK: Designed and conceived the study, data analysis and editing.

MUI: Helped in data collection and manuscript writing.

IA: Helped in data collection, statistical analysis.

MUR: Analysis of data and final approval.

MUR: Responsible and accountable for the accuracy and integrity of the work. 